\title{
Environmental TEM Study of Oxidation Processes of Catalytic Nanoparticles
}

\author{
L. Kovarik ${ }^{1,2 *}$, Z. Wei ${ }^{2}$, C.H.F. Peden ${ }^{2}$, J. Szanyi ${ }^{2}$ \\ 1 Environmental Molecular Sciences Laboratory, Pacific Northwest National Laboratory, P.O. \\ Box 999, Richland, Washington 99352 \\ ${ }^{2}$ Institute for Integrated Catalysis, Pacific Northwest National Laboratory, P.O. Box 999, \\ Richland, Washington 99352 \\ * Corresponding author: libor.kovarik@pnnl.gov
}

Supported transition metal nanoparticles are extensively used in catalytic applications due to their high surface to volume ratio and high concentration of low coordinated atomic sites. When exposed to elevated temperatures and gas environments, a range of thermally activated processes can lead to morphological, structural and surface transformations, which have an effect on catalytic properties. Understanding these transformations under in-situ conditions is critical for rationalization of structure-property relationships, and essential for future advancement of catalytic technologies.

The present work focuses on studying the mechanism of oxidation/reduction processes of $\mathrm{Pd}$ nanoparticles supported on various substrates, including $\mathrm{CeO}_{2}, \gamma / \delta-\mathrm{Al}_{2} \mathrm{O}_{3}, \mathrm{ZrO}_{2}$ and $\mathrm{SiO}_{2}$. Our work relies on the use of in-situ Transmission Electron Microscopy. The TEM observations were performed with environmental FEI Titan 80-300 equipped with a CEOS $\mathrm{C}_{\mathrm{s}}$-image corrector, and operated at $80 \mathrm{kV}$ and $300 \mathrm{kV}$ under a set of well-defined environmental conditions in the pressure range of $\sim 10^{-3}-10^{1}$ mbars. The samples were heated with MEMS based Aduro ${ }^{\mathrm{TM}}$ Protochips holder up to $500^{\circ} \mathrm{C}$. The composition and switching of gasses was controlled with a custom-built gas control unit.

In the first part of the presentation we will discuss the mechanism of oxidation of Pd nanoparticles as a function of temperature, with a specific focus on understanding the nucleation and growth of PdO oxide phase. An example of high-resolution TEM observations that depicts atomic level process associated with the transformation of $\mathrm{Pd}$ to $\mathrm{PdO}$ on $\mathrm{CeO}_{2}$ substrate is shown in Figure 1. In this particular example, the observations show transformation of $\mathrm{Pd}$ nanoparticle to $\mathrm{PdO}$ during an exposure to $\sim 1 \mathrm{mbar}$ of $\mathrm{O}_{2}$ at $400^{\circ} \mathrm{C}$. The initial step of the transformation includes the formation of surface oxide (Fig.1(b)), and subsequent nucleation and growth of PdO as shown in Fig1(c) and planar front transformation. Mechanistic aspect of oxygen uptake by $\mathrm{Pd}$, and model of $\mathrm{PdO}$ formation will be presented. As a part of the presentation, we also discuss the role of support, and show how coherency strains from the substrate, and chemical interaction with the substrate can lead to significant changes in the initial stages of oxide formation. Lastly, the effect of electron beam will be discussed, and we will present examples where the electron beam exposure leads to imaging artifacts [5]. 
[1] This research was supported by Laboratory Directed Research and Development Program at PNNL, and by the U.S. DOE, Office of Basic Energy Sciences, Division of Chemical Sciences, Biosciences and Geosciences. The work was conducted in the William R. Wiley Environmental Molecular Sciences Laboratory (EMSL), a national scientific user facility sponsored by DOE's Office of Biological and Environmental Research and located at PNNL.
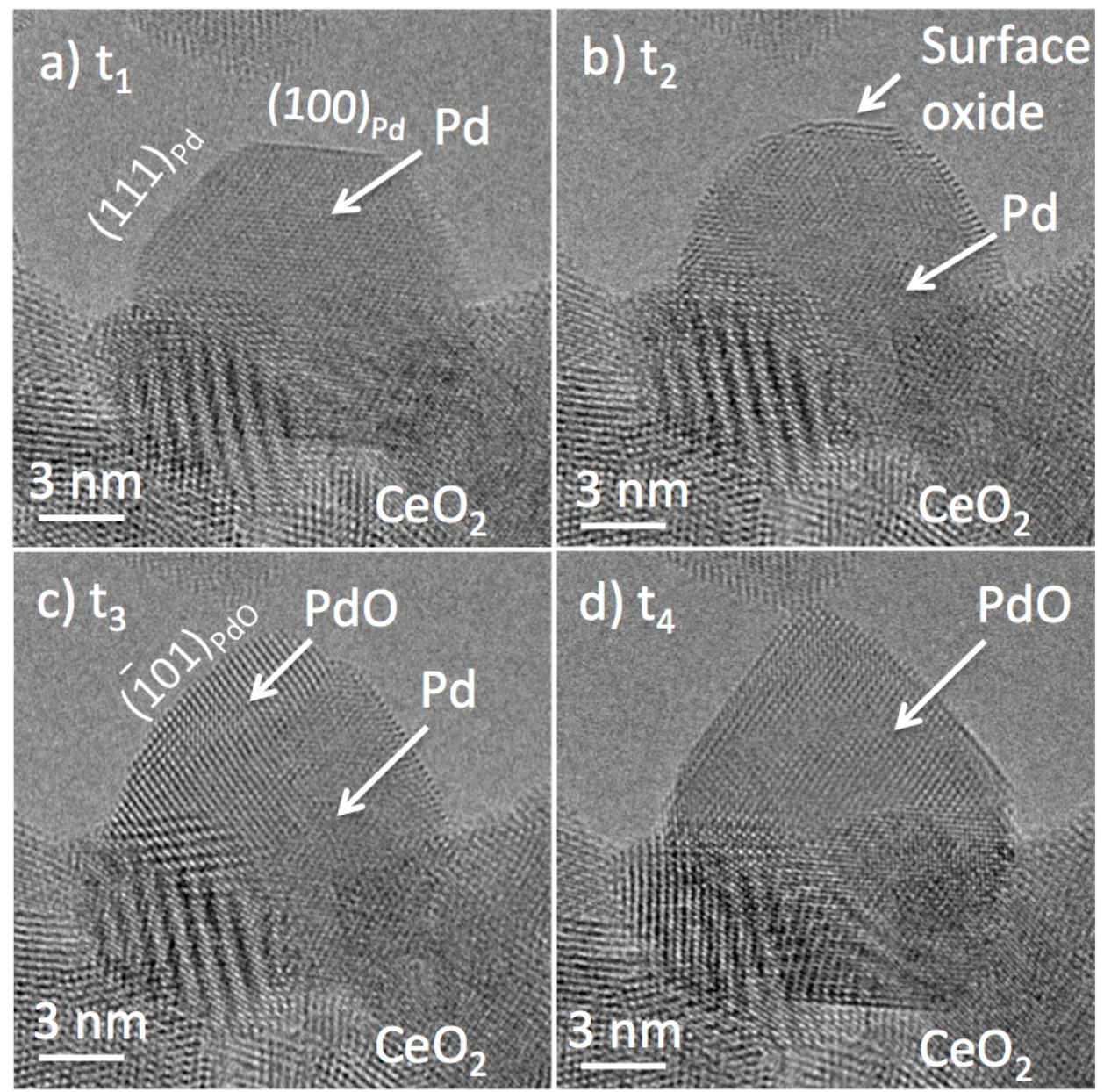

Fig.1. High resolution ETEM observation of $\mathrm{Pd}$ to $\mathrm{PdO}$ transformation at oxygen partial pressure of $\sim 1$ mbar and temperature of $400^{\circ} \mathrm{C}$ (a) Initial Pd nanoparticle supported on $\mathrm{CeO}_{2}$. (b) Transition period corresponding to the formation of surface oxide (c) Transition period corresponding to growth $\mathrm{PdO}(\mathrm{d})$ Final stage of transformation corresponding to the formation of $\mathrm{PdO}$. 